\title{
Academic neurology and industry: open doors or firewalls?
}

\author{
John W Griffin
}

Recent New York Times articles linking industry money with physicians have the voyeuristic appeal of stories in celebrity magazines suggesting dalliances between notorious and indiscreet movie stars (I have only been told of such magazines; I have of course never actually read one). Times reporters Gardiner Harris and Janet Roberts, drawing from an article in the Journal of the American Medical Association, analyzed payments by drug companies to physicians in Minnesota, where public disclosure is mandatory. Psychiatrists and neurologists were among the top recipients, with a median payment to neurologists of more than US $\$ 3,780$ over 8 years. More than 100 physicians exceeded $\$ 100,000$ in payments. Much of this sum was for nominally educational activities, such as speaking at drug dinners, at which the presentation text and slides are typically prepared by drug companies. We have read elsewhere of clinical trial investigators who received large consulting fees from companies whose drugs they were studying, of members of advisory panels to the US FDA who were perceived to have conflicts of interest, of those framing practice guidelines who received income from companies, and of authors of clinical research reports who failed to disclose their financial relationships with companies on whose drugs they were reporting. Also, in spite of pharmaceutical industry guidelines, petty incentives-ranging from lunches and trips to valueless 'gifts' such as pens labeled with a drug company name-remain ubiquitous. These ugly pictures demean the participants, and they have the potential to erode trust in clinical science and in medication recommendations made by physicians.

Some of the most thoughtful and ethically sensitive neurologists with whom I talk are embarrassed by these stories, yet they argue that there is one area in which we need closer relations with industry. These academic neuroscientists are frustrated by the barriers to turning their discoveries into treatments. They want free and open communication with company
The nub of the

issue is ... how to

simultaneously

encourage

interactions in

basic discovery,

prevent conflict

in clinical

studies, and

minimize

incursions

of marketing

activities into

education

JW Griffin is the

Editor-in-Chief

of Nature Clinical

Practice Neurology,

and Professor

of Neurology,

Neuroscience,

and Pathology, and

Director of the Brain

Sciences Institute,

at Johns Hopkins

University School of

Medicine, Baltimore,

$M D, U S A$.

\section{Competing interests}

The author declared he has

no competing interests.

www.nature.com/clinicalpractice doi:10.1038/ncpneuro0523 scientists about joint projects, with fewer forms, fewer delays, and fewer lawyers paid to constrain communication. Confidentiality and intellectual property issues lie at the root of these problems, and they are the toeholds by which lawyers enter the conversations.

The nub of the issue is the question of how to simultaneously encourage interactions in basic discovery, prevent conflict in clinical studies, and minimize incursions of marketing activities into education. We need to foster industry investment in the first instance, accept it under guidelines in the second, and stringently regulate it in the third. In addition, all stakeholders-neurologists, institutions, press and public-need to recognize the distinctions in uses of industry money. Many press reports conflate marketing money that goes to personal income, such as payment in speakers' bureaus, and research grants.

Academic institutions and industry need to reform their approaches to confidentiality and intellectual property to allow basic scientists to cooperate freely on specific research projects. Creative master agreements should reduce time wasted on sterile legal issues. In clinical studies there will be a perception of conflict if investigators are receiving too much money for their efforts. Helpful initiatives in this regard include passing salary support through the institutions as 'per cent effort', not allowing paid consultancies or speaking roles during trials, and precluding individuals who have equity stakes in companies from being major investigators in trials involving that company. Ultimately, transparency remains the key; we should declare all relationships fully and enthusiastically, and encourage public reporting of relationships through sunshine laws. We should ask ourselves how any of our interactions with industry would be perceived if reported by Harris and Roberts.

Industry and the neuropsychiatric academia need each other. The ideal balance would be open doors in basic discovery, arm's-length relationships in clinical research, and firewalls between marketing and academia. 